\title{
Teletrabajo y dolor musculoesquelético en el contexto de la crisis por COVID-19
}

Telework and musculoskeletal pain in the context of the COVID-19 crisis

\author{
Cristhian Santiago-Bazán 1,a
}

\section{Sr. Editor:}

La enfermedad del coronavirus, posteriormente ocasionada por el virus SARS-CoV-2 ha generado a nivel mundial una nueva pandemia. Actualmente se están reuniendo esfuerzos para su control. Esta enfermedad ha llevado a un aumento de número de infectados en el mundo (1). Así mismo, en el Perú, desde el primer caso reportado en marzo del 2020 hasta febrero del $2021^{(2)}$, se han venido reportando 1'252,137 casos según el Ministerio de Salud de Perú, conllevando a muchos países a decretar un confinamiento social obligatorio como medida para poder frenar el número de casos de contagio. Además, podría tener consecuencias en el sistema musculoesquelético del trabajador (3).

El trabajo desde casa requiere la consideración de las mismas pautas posturales al igual que el trabajo de oficina y computadoras. Es por ello, para evitar el estrés mental y físico se recomienda un diseño ergonómico de la estación de trabajo. Además, la organización del tiempo de trabajo (estructuración de la jornada laboral, adherencia a las unidades de descanso y regeneración, evitando perturbaciones e interrupciones) implica adecuar el lugar de trabajo dentro del hogar para que se pueda tener un entorno saludable ${ }^{(4)}$ y prevenir algún tipo de lesión musculoesquelética en la espalda.

Por otro lado, este tipo de trabajo en el Perú surge como medida excepcional y temporal a raíz del estado de emergencia por la covid-19, donde los trabajadores aplican a este diseño ergonómico a fin de cumplir sus labores desde sus domicilios y, en la medida que sea posible, preservar la estabilidad en el empleo, la productividad del empleador, evitando riesgos de contagio en el centro laboral o durante su traslado, protegiendo la salud de los trabajadores y a sus familias frente a los contagios por la covid-19 ${ }^{(5)}$.

El teletrabajo desde casa o el trabajo móvil pueden conllevar a posibles riesgos e impactos para la salud respecto a un uso "no responsable". Por otro lado, este sistema de trabajo puede convertirse en un riesgo laboral en el empleado debido a una mala práctica ergonómica, provocando problemas musculoesqueléticos, visuales y psicosociales ${ }^{(6)(7)}$.

\footnotetext{
${ }^{1}$ Centro de Rehabilitación Integral Física Funcional. Lima, Perú.

a Doctor en educación. Tecnólogo Médico en Terapia física y rehabilitación

ORCID: https://orcid.org/0000-0001-9073-4785
} 
El teletrabajo ocasiona trastornos musculoesqueléticos a consecuencia de las posturas incorrectas y el mantenimiento prolongado de posturas estáticas de sedestación, el lugar y la posición de los equipos de trabajo (mesa, silla, ordenador, teclado, superficie de trabajo y superficie disponible en el entorno), factores organizativos como el tiempo de trabajo o las pausas ${ }^{(8)}$

Es necesario tener en consideración que la espalda es una región vulnerable a este tipo de lesión musculoesquelética, porque es una estructura humana tan compleja y bien armada, la cual necesita cuidarse para que no se produzcan alteraciones anatómicas y funcionales que la vayan lesionando, lo cual traería como resultado el dolor y deterioro de su biomecánica, siendo motivo de preocupación en la salud pública ${ }^{(9)}$.

Finalmente, el teletrabajo es una forma eficaz de superar las limitaciones del trabajo presencial generadas por la pandemia, el cual puede producir efectos positivos como negativos al momento de la implementación de esta modalidad de trabajo. Existe la posibilidad de que no solo se vea afectada la salud mental sino también la salud física ${ }^{\left({ }^{10}\right)}$. La predisposición a tener algún tipo lesiones musculoesqueléticas en la espalda a causa de la adopción de posturas inadecuadas al momento de realizar este tipo de actividad laboral, puede conllevar a una discapacidad física.

Conflictos de interés: El autor declara no tener conflicto de interés.

\section{Fuentes de financiamiento: Autofinanciado}

\section{REFERENCIAS BIBLIOGRÁFICAS}

1. Gutierrez BJ, Aruquipa Quispe CJ. Covid-19: aspectos virologicos y patogenesis. Revista Científica Ciencia Médica.2020; 23(1): 77-86.

2. Sala Situacional Covid 19 Perú [Internet]. 2021. Disponible en: https://covid19.minsa.gob.pe/sala_situacional.asp

3. Rodríguez-Nogueira Ó, Leirós-Rodríguez R, Benítez-Andrades JA, Álvarez-. Álvarez MJ, Marqués-Sánchez P, Pinto-Carral A. Musculoskeletal Pain and Teleworking in Times of the COVID-19: Analysis of the Impact on the Workers at Two Spanish Universities. Rev. Int J Environ Res Public Health. 2020;18(1):31. Doi: 10.3390/ijerph18010031.

4. Mojtahedzadeh N, Rohwer E, Lengen J, Harth V, Mache S. Gesundheitsfördernde Arbeitsgestaltung im Homeoffice im Kontext der COVID-19-Pandemie. Rev Zentralbl Arbeitsmed Arbeitsschutz Ergon. 2021;1-6. Doi:10.1007/ s40664-020-00419-1

5. Delgado de la Matta, Ángel L. El trabajo remoto en el Perú en tiempo de Covid. Rev. Iberoamericana De Derecho Del Trabajo Y De La Seguridad Social.2020; 2(3): 73-84. Disponible en: http://aidtss.org/revistaiberoamericana/index.php/main/article/view/34

6. González-Menéndez E, López-González MJ, González Menéndez S, García González G y Álvarez Bayona T. Principales consecuencias para la salud derivadas del uso continuado de nuevos dispositivos electrónicos con PVD. Rev Esp Salud Pública. 2019;9. Disponible en: https://www.mscbs. gob.es/biblioPublic/publicaciones/recursos_propios/resp/revista_cdrom/ VOL93/C_ESPECIALES/RS93C_201908062.pdf

7. Rappaccioli Salinas R, Hernández Flores F, Zamora Madrigal A. Repercusiones en la salud a causa del teletrabajo. Rev.méd.sinerg.2021;6(2). Doi: https://doi.org/10.31434/rms.v6i2.641

8. Estándares OISS de Seguridad y Salud en el trabajo EOSyS. Prevención de riesgos Laborales en el Teletrabajo [Internet]. 2019. Disponible en: https://oiss.org/wp-content/uploads/2019/06/EOSyS-18-PRL-en-el-teletrabajo.-doc.pdf
9. Reguera Rodríguez Rolando, Socorro Santana Miriam de la Caridad Jordán Padrón Marena, García Peñate Gladys, Saavedra Jordán Liz Mariam. Dolor de espalda y malas posturas, ¿un problema para la salud?. Rev.Med.Electrón. 2018; 40(3) 833-838. Disponible en: http://scielo.sld. cu/scielo.php?script=sci_arttext\&pid=S1684-18242018000300026\&ln$\mathrm{g}=\mathrm{es}$

10. Morilla-Luchena A, Muñoz-Moreno R, Chaves-Montero A, Vázquez-Aguado O. Teletrabajo y Servicios Sociales en España durante la Pandemia COVID-19. Int J Environ Res Salud Pública. 2021 15;18(2)725. Doi: 10.3390/ijerph18020725. 